\title{
EVALUASI FASILITAS DARATAN PELABUHAN PENYEBERANGAN TANJUNG KALIAN MUNTOK KABUPATEN BANGKA BARAT
}

\author{
Chairul insani I, ATD,MM \\ Dosen STTD \\ J1. Raya Setu No. 89, Bekasi \\ Telp./Fax : (021) 8254640
}

\author{
Bambang Setiawan, ST,MT \\ Dosen STTD \\ Jl. Raya Setu No. 89, Bekasi \\ Telp./Fax : (021) 8254640
}

\author{
Drs. Anwar Tuip, MM \\ Dosen STTD \\ J1. Raya Setu No. 89, Bekasi \\ Telp./Fax : (021) 8254640 \\ Purboyo,MM \\ Dosen STTD \\ Jl. Raya Setu No. 89, Bekasi \\ Telp./Fax : (021) 8254640
}

\begin{abstract}
Tanjung Kalian Crossing Port, Muntok is a Crossing Port that serves the Tanjung Kalian - Tanjung Api-api line, which is managed by PT. ASDP Indonesia Ferry (Persero) Bangka Branch. This port is very closely related to improving the economy and development of the Bangka-Belitung community, because of its role as a gateway for trade and tourism. The purpose of this study is to determine the condition of facilities such as the existence of Gangway and placement of ticket sales counters for passengers in accordance with Minister of Transportation Regulation No. 29 In 2016, and Appendix II of the Directorate General of Land Transportation Regulation Number SK.2681 / AP / DRJD / 2006 concerning the operation of the Port of Intersection on September 4, 2006, procedures for Services for Passengers. To improve service quality for users of port services, it is necessary to pay attention to the condition of facilities existing land port while the current conditions still have some disadvantages such as the absence of an alley used for pedestrians to and from ships. In order not to interfere with vehicles that will get out of the ship, as well as placement of passenger counters that are not suitable so as to make passengers reluctant to buy tickets in advance which results when the ship is ready to load them crammed to buy tickets.
\end{abstract}

Keywords: Port, alley, counter.

\begin{abstract}
ABSTRAKSI
Pelabuhan Crossing Tanjung Kalian, Muntok adalah Crossing Port yang melayani jalur Tanjung Kalian - Tanjung Api-api, yang dikelola oleh PT. ASDP Indonesia Ferry (Persero) Cabang Bangka. Pelabuhan ini sangat erat kaitannya dengan peningkatan ekonomi dan perkembangan masyarakat Bangka-Belitung, karena perannya sebagai pintu gerbang untuk perdagangan dan pariwisata.Tujuan penelitian ini adalah untuk mengetahui kondisi fasilitas seperti keberadaan Gangway dan penempatan konter penjualan tiket untuk penumpang sesuai dengan Peraturan Menteri Perhubungan Nomor 29 Tahun 2016, dan Lampiran II Direktorat Jenderal Perhubungan Darat Peraturan Nomor SK.2681 / AP / DRJD / 2006 tentang pengoperasian Pelabuhan Persimpangan pada tanggal 4 September 2006, prosedur untuk Layanan bagi Penumpang.Untuk meningkatkan kualitas layanan bagi pengguna jasa pelabuhan, perlu memperhatikan kondisi fasilitas darat pelabuhan yang ada sementara kondisi saat ini
\end{abstract}


masih memiliki beberapa kerugian seperti tidak adanya gang yang digunakan untuk pejalan kaki ke dan dari kapal. Agar tidak mengganggu kendaraan yang akan keluar dari kapal, serta penempatan counter penumpang yang tidak cocok sehingga membuat penumpang enggan membeli tiket terlebih dahulu yang berakibat ketika kapal siap memuat mereka berdesakan untuk membeli tiket.

Kata kunci: Port, gang, counter.

\section{PENDAHULUAN}

\section{Latar Belakang}

Pelabuhan Penyeberangan Tanjung Kalian terletak di Kabupaten Bangka Barat yang berada dalam wilayah Provinsi Bangka Belitung. Secara administrasi Pelabuhan Penyeberangan Tanjung Kalian terletak dalam wilayah Kota Muntok. Secara geografis Kabupaten Muntok berada pada daerah yang sangat strategis apabila dlihat dari karakteristik wilayah yang lebih luas, karena lokasi ini menjadi pintu keluar dan masuknya berbagai macam kebutuhan yang datang maupun menuju ke Pulau Sumatera. Oleh sebab itu, Pelabuhan Penyeberangan Tanjung Kalian ini yang memberikan dampak yang besar terhadap proses pertumbuhan ekonomi dan perkembangan wilayah tersebut. Pelabuhan Penyeberangan Tanjung Kalian dikelola dan diselenggarakan oleh PT ASDP Indonesia Ferry (Persero) Cabang Bangka dan pada bagian prasarananya dikelola oleh PT.ASDP Indonesia Ferry (Persero) dan beberapa Perusahaan Pelayaran Swasta, untuk melayani kapal-kapal penyeberangan Tanjung Kalian - Tanjung Api-api dengan lintas komersil membutuhkan jarak tempuh 30 mil laut yang dilayani oleh 8 unit kapal penyeberangan dengan waktu tempuh \pm 4 jam. Pelabuhan Penyeberangan Tanjung Kalian dirasakan semakin penting dan strategis terhadap kemajuan dan perkembangan daerah, maka sudah seharusnya dapat terus ditingkatkan baik dari segi pelayanan, kapal dan fasilitas pendukung.

Dalam penelitian yang dilakukan di Pelabuhan Penyeberangan Tanjung Kalian terdapat beberapa permasalahan yaitu:

1. Apakah dengan tidak adanya Gangway akan mempengaruhi naik dan turun penumpang ke kapal ?

2. Apakah penempatan loket penumpang dan kendaraan yang tidak sesuai dengan Peraturan Dirjen Perhubungan Darat Nomor SK.2681/AP/DRJD/2006 akan mempengaruhi waktu bongkar muat kapal ?

3. Bagaimana pengaturan penumpang naik dan turun agar tidak mengganggu kendaraan yang akan keluar dan masuk kapal

Penelitian ini diharapkan dapat memberikan manfaat antara lain :

a. Bagi peneliti, merupakan salah satu upaya dalam rangka meningkatkan pengetahuan peneliti khususnya pada perencanaan fasilitas daratan pelabuhan penyebarangan. 
b. Bagi Lembaga Pendidikan, sebagai bahan pendidikan guna kemajuan terhadap pembelajaran transportasi khususnya di pelabuhan penyeberangan dan sebagai referensi untuk penelitian selanjutnya.

c. Bagi Instansi terkait/pembina sebagai bahan masukan dalam rangka peningkatan pelayanan terhadap pengguna jasa pelabuhan penyeberangan.

\section{Deskripsi Obyek Penelitian}

Yang menjadi sarana transportasi pada angkutan penyeberangan Tanjung Kalian Bangka Barat, dikelola oleh PT. ASDP Indonesia Ferry (Persero) cabang Bangka merupakan kapal tipe Ro-Ro dan Kapal cepat dengan jumlah kapal yang beroperasi 8 (delapan) kapal tipe Ro-Ro dan 1 (satu) buah kapal cepat.

Berikut adalah data kapal yang beroperasi pada Pelabuhan Penyeberangan Tanjung Kalian :

Karakteristik Kapal Penyeberangan di Tanjung Kalian

\begin{tabular}{|c|c|c|c|c|c|c|c|}
\hline \multirow[b]{2}{*}{ No } & \multirow{2}{*}{ NAMA KAPAL } & \multirow{2}{*}{ PERUSAHAAN } & \multirow{2}{*}{ THN } & \multirow{2}{*}{$\begin{array}{c}\text { GR } \\
\text { T }\end{array}$} & \multirow{2}{*}{$\begin{array}{c}\text { KNO } \\
\text { T }\end{array}$} & \multicolumn{2}{|c|}{ KAPASITAS } \\
\hline & & & & & & PNP & $\begin{array}{c}\text { KEN } \\
\text { D }\end{array}$ \\
\hline (1) & (2) & (3) & (4) & (5) & (6) & (7) & $(8)$ \\
\hline 1 & $\begin{array}{c}\text { KMP. } \\
\text { MENUMBING } \\
\text { RAYA } \\
\end{array}$ & $\begin{array}{c}\text { PT. ASDP } \\
\text { Indonesia Ferry } \\
\text { (Persero) }\end{array}$ & 2008 & 652 & 8 & 204 & 19 \\
\hline 2 & $\begin{array}{l}\text { KMP. KUALA } \\
\text { BATEE II }\end{array}$ & $\begin{array}{c}\text { PT. ASDP } \\
\text { Indonesia Ferry } \\
\text { (Persero) }\end{array}$ & 1991 & 464 & 9 & 300 & 20 \\
\hline 3 & $\begin{array}{c}\text { KMP. SETYA } \\
\text { KENCANA I }\end{array}$ & $\begin{array}{c}\text { PT. DHARMA } \\
\text { LAUTAN UTAMA }\end{array}$ & 1984 & 806 & 8 & 350 & 30 \\
\hline 4 & $\begin{array}{c}\text { KMP. DHARMA } \\
\text { SENTOSA }\end{array}$ & $\begin{array}{c}\text { PT. DHARMA } \\
\text { LAUTAN UTAMA }\end{array}$ & 1984 & 536 & 8 & 200 & 23 \\
\hline 5 & $\begin{array}{l}\text { KMP. MUTIARA } \\
\text { PERTWI II }\end{array}$ & $\begin{array}{c}\text { PT. ATOSIM } \\
\text { LAMPUNG } \\
\text { PELAYARAN } \\
\end{array}$ & 1995 & 303 & 8 & 250 & 20 \\
\hline 6 & $\begin{array}{l}\text { KMP. PERMATA } \\
\text { LESTARI }\end{array}$ & $\begin{array}{l}\text { PT. ATOSIM } \\
\text { LAMPUNG } \\
\text { PELAYARAN }\end{array}$ & 1995 & 357 & 8 & 40 & 27 \\
\hline 7 & $\begin{array}{l}\text { KMP. JEMBATAN } \\
\text { MUSI I }\end{array}$ & $\begin{array}{l}\text { PT. JEMBATAN } \\
\text { MARITIM }\end{array}$ & 1972 & 406 & 8 & 250 & 25 \\
\hline 8 & $\begin{array}{c}\text { KMP. ADHI } \\
\text { SWADARMA }\end{array}$ & $\begin{array}{c}\text { PT. PRIMA } \\
\text { EKSEKUTIF }\end{array}$ & 1996 & 511 & 8 & 200 & 20 \\
\hline 9. & $\begin{array}{l}\text { KMC. EKSPRESS } \\
\text { BAHARI } 8\end{array}$ & $\begin{array}{l}\text { PT. SAKTI INTI } \\
\text { MAKMUR }\end{array}$ & 2003 & 172 & 30 & 332 & \\
\hline
\end{tabular}




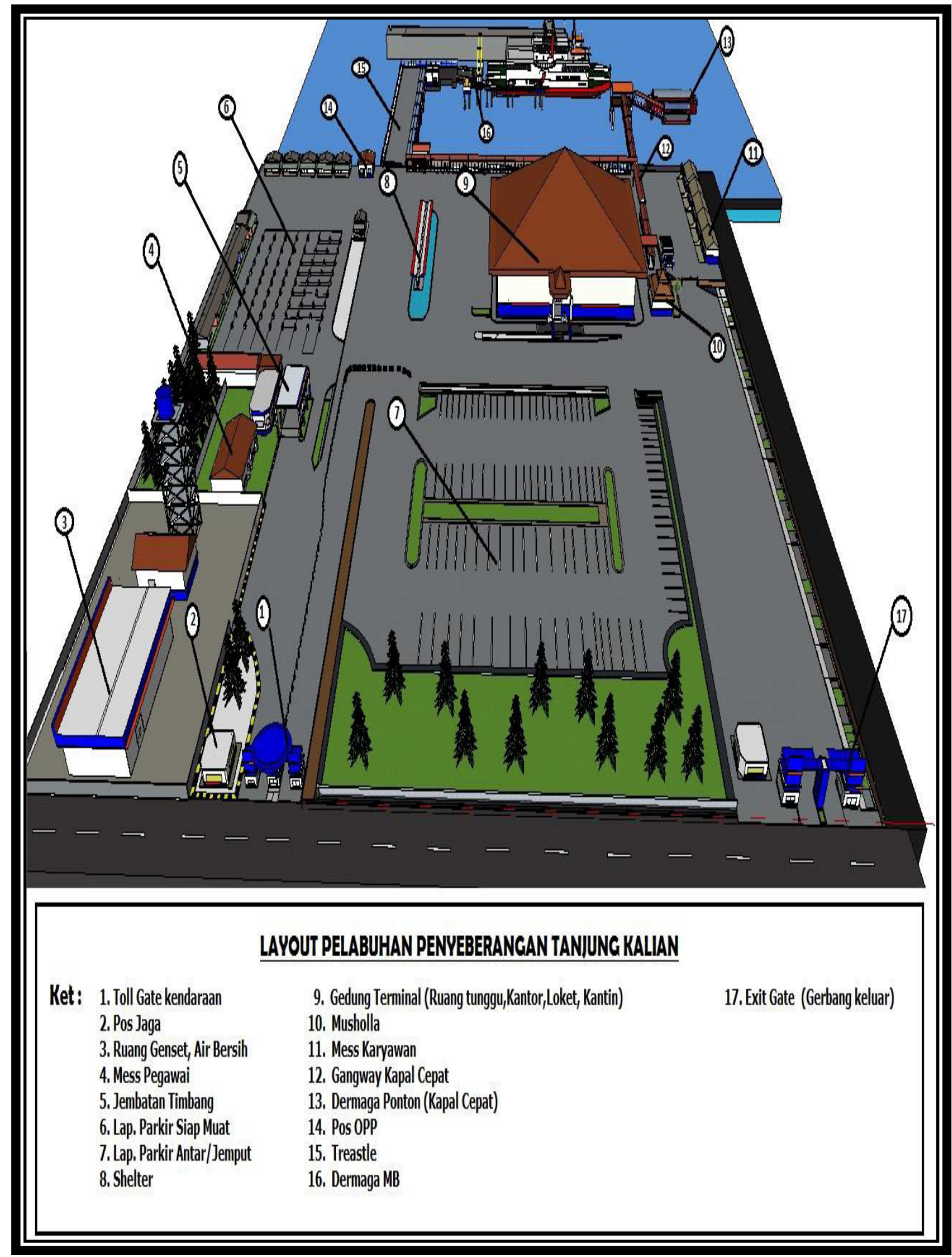

Lay Out Pelabuhan 


\section{Produktivitas Angkutan}

Produktivitas tahunan Kapal Ferry pada Pelabuhan Penyeberangan Tanjung Kalian 5 (lima) tahun terakhir, Tahun 2013 - 2017.

Data Produktivitas Keberangkatan

Penumpang dan Kendaraan Tahun 2013-2017

\begin{tabular}{|c|c|c|c|c|c|c|c|c|}
\hline No & & Uraian & 2013 & 2014 & 2015 & 2016 & 2017 & Jumlah \\
\hline 1 & \multicolumn{7}{|c|}{ PENUMPANG KAPAL RORO } & \\
\hline & \multicolumn{2}{|c|}{ Dewasa } & 57514 & 67089 & 93995 & 98468 & 118341 & 429525 \\
\hline & \multicolumn{2}{|c|}{ Anak - anak } & 420 & 957 & 1449 & 1595 & 2761 & 5882 \\
\hline \multirow{13}{*}{2} & \multicolumn{7}{|c|}{ KENDARAAN } & \\
\hline & a. & Gol. I & - & - & 4 & 1 & 5 & 10 \\
\hline & b. & Gol. II & 10861 & 10484 & 12201 & 10750 & 11384 & 55680 \\
\hline & c. & Gol. III & 0 & 23 & 28 & 69 & 74 & 194 \\
\hline & $\mathrm{d}$. & $\begin{array}{l}\text { Gol. IV } \\
\text { (pnp) }\end{array}$ & 3368 & 3776 & 11203 & 10654 & 11780 & 40781 \\
\hline & e. & $\begin{array}{l}\text { Gol. IV } \\
\text { (brg) }\end{array}$ & 1803 & 1723 & 3678 & 3687 & 3831 & 14722 \\
\hline & f. & $\begin{array}{l}\text { Gol. V } \\
\text { (pnp) }\end{array}$ & 112 & 106 & 208 & 163 & 168 & 757 \\
\hline & g. & Gol. V (brg) & 8678 & 7819 & 10284 & 10443 & 13833 & 51057 \\
\hline & h. & $\begin{array}{l}\text { Gol. VI } \\
\text { (pnp) }\end{array}$ & 2 & 1 & 5 & 16 & 5 & 29 \\
\hline & i. & $\begin{array}{l}\text { Gol. VI } \\
\text { (brg) }\end{array}$ & 298 & 398 & 904 & 911 & 931 & 16344 \\
\hline & $\mathrm{j}$. & Gol. VII & 19 & 32 & 51 & 83 & 86 & 271 \\
\hline & $\mathrm{k}$. & Gol. VIII & 1 & - & - & - & 1 & 2 \\
\hline & 1. & Gol. IX & - & - & - & - & - & - \\
\hline
\end{tabular}


PRODUKTIVITAS PENUMPANG/TRIP/KAPAL

TAHUN 2013-2017

\begin{tabular}{|c|c|c|c|c|c|c|}
\hline \multirow{2}{*}{ No } & \multirow{2}{*}{ Tahun } & $\begin{array}{c}\text { Trip } \\
\text { Kapal/Tahu } \\
\mathrm{n}\end{array}$ & \multicolumn{2}{|c|}{ Penumpang } & \multirow{2}{*}{$\begin{array}{c}\text { Jumlah } \\
\text { Penumpang }\end{array}$} & $\begin{array}{c}\text { Pnp/Trip } \\
\text { Kapal }\end{array}$ \\
& & Dewasa & Anak-anak & & \\
\hline 1 & 2013 & 1148 & 57094 & 420 & 57514 & 50,10 \\
\hline 2 & 2014 & 1151 & 66132 & 957 & 67089 & 58,29 \\
\hline 3 & 2015 & 1444 & 92546 & 1449 & 93995 & 65,09 \\
\hline 4 & 2016 & 1413 & 96873 & 1595 & 98468 & 69,69 \\
\hline 5 & 2017 & 1829 & 115580 & 2761 & 118341 & 64,70 \\
\hline
\end{tabular}

Produktifitas Penumpang Kapal Ferry Pada Pelabuhan

Tanjung Kalian 5 tahun terakhir

\begin{tabular}{|c|c|c|c|c|c|c|}
\hline \multirow{2}{*}{ No } & \multirow{2}{*}{ Tahun } & \multirow{2}{*}{$\begin{array}{c}\text { Trip } \\
\text { Kapal/Tahu } \\
\mathrm{n}\end{array}$} & \multicolumn{2}{|c|}{ Penumpang } & \multirow{2}{*}{$\begin{array}{c}\text { Jumlah } \\
\text { Penumpang }\end{array}$} & $\begin{array}{c}\text { Pnp/Trip } \\
\text { Kapal }\end{array}$ \\
\cline { 5 - 6 } & & Dewasa & Anak-anak & & 50 \\
\hline 2 & 2013 & 1148 & 57094 & 420 & 57514 & 58 \\
\hline 3 & 2015 & 1151 & 66132 & 957 & 67089 & 65 \\
\hline 4 & 2016 & 1413 & 96873 & 1595 & 98468 & 70 \\
\hline 5 & 2017 & 1829 & 115580 & 2761 & 118341 & 65 \\
\hline
\end{tabular}


Produktifitas Penumpang Kapal Cepat Pada Pelabuhan

Tanjung Kalian 5 tahun terakhir

\begin{tabular}{|c|c|c|c|c|c|c|}
\hline \multirow{2}{*}{ No } & \multirow{2}{*}{ Tahun } & \multirow{2}{*}{$\begin{array}{c}\text { Trip } \\
\text { Kapal/Tahu } \\
\mathrm{n}\end{array}$} & \multicolumn{2}{|c|}{ Penumpang } & \multirow{2}{*}{$\begin{array}{c}\text { Jumlah } \\
\text { Penumpang }\end{array}$} & \multirow{2}{*}{$\begin{array}{c}\text { Pnp/Trip } \\
\text { Kapal }\end{array}$} \\
\hline & & & Dewasa & Anak-anak & & \\
\hline 1 & 2013 & 192 & 44162 & 1987 & 46149 & 240 \\
\hline 2 & 2014 & 192 & 41406 & 2012 & 43418 & 226 \\
\hline 3 & 2015 & 192 & 39134 & 1840 & 40974 & 213 \\
\hline 4 & 2016 & 192 & 37841 & 1745 & 39586 & 206 \\
\hline 5 & 2017 & 192 & 36001 & 1698 & 37699 & 196 \\
\hline \multicolumn{6}{|c|}{ Rata-rata } & 216 \\
\hline
\end{tabular}

Dari data diatas diketahui bahwa jenis kapal yang beroperasi pada pelabuhan penyeberangan Tanjung Kalian terdiri dari kapal ferry dan kapal cepat. setelah melakukan perhitungan diketahui bahwa jumlah rata-rata keberangkatan penumpang kapal ferry sebanyak 62 penumpang/trip, sedangkan untuk kapal cepat didapatkan jumlah rata-rata keberangkatan penumpang sebanyak 216 penumpang/trip. Jika dijumlahkan maka didapatkan hasil total sebesar 278 penumpang per-trip, baik untuk kapal ferry maupun kapal cepat.

\section{Analisa Lapangan Parkir Siap Muat}

Pelabuhan penyeberangan Tanjung Kalian memiliki lapangan parkir siap muat kendaraan dengan luasan $1.600 \mathrm{~m}^{2}$, untuk mengetahui kebutuhan lapangan parkir siap muat kendaraan ke kapal maka digunakan perhitungan sebagai berikut :

a. Kebutuhan Lapangan Parkir Siap Muat, Untuk menghitung kebutuhan lapangan parkir siap muat digunakan rumus sebagai berikut :

Keterangan :

$$
\mathbf{A}=\mathbf{a} \cdot \mathbf{n} \cdot \mathbf{N} \cdot \mathbf{x} \cdot \mathbf{y}
$$

A = Areal lapangan parkir $\left(\mathrm{m}^{2}\right)$

a = Luas yang dibutuhkan untuk kendaraan

Truk 8 Ton (Golongan VI) $=60 \mathrm{~m}^{2}$

Truk 4 Ton (Golongan V) $=45 \mathrm{~m}^{2}$

Truk 2 Ton (Golongan IV) $=25 \mathrm{~m}^{2}$

$\mathrm{n}=$ Jumlah kendaraan dalam 1 kapal ferry (25 unit kendaraan campuran

dan

8 sepeda motor diambil dari kapasitas kendaraan campuran terbanyak yaitu

KMP. Satya Kencana)

$\mathrm{x} \quad=$ rata-rata pemanfaatan $(1,0)$ 
$\mathrm{y} \quad=$ rasio konsentrasi $(1,0-1,6)$

KENDARAAN CAMPURAN TERBANYAK PADA KAPAL KMP. SATYA KENCANA YAITU :

kendaraan golongan $\mathrm{II}=8$ Unit $\mathrm{x} 2,8 \mathrm{SUP} \quad=22,4 \mathrm{SUP}$

kendaraan golongan IVA $=6$ Unit $x 21,63 \mathrm{SUP}=129,78 \mathrm{SUP}$

kendaraan golongan IVB $=2$ Unit $\times 17,98 \mathrm{SUP}=35,96 \mathrm{SUP}$

kendaraan golongan $\mathrm{VB}=14$ Unit $\times 31,55 \mathrm{SUP}=441,7 \mathrm{SUP}$

kendaraan golongan VIB $=2$ Unit $x$ 52,33 SUP $=104,66$ SUP

kendaraan golongan VII $=1$ Unit $x 66,03 \mathrm{SUP}=66,03 \mathrm{SUP}$

Maka :

Luas kebutuhan= Jlh luas kebutuhan (SUP) x 1 SUP

$=(22,4+129,78+35,96+441,7+104,66+66,03) \times 0,73 \mathrm{~m}^{2}=584,38 \mathrm{~m}^{2}$

Maka luasan lapangan parkir siap muat dapat di hitung sebagai berikut:

$$
\begin{aligned}
A & =a \cdot n \cdot N \cdot x \cdot y \\
& =584,38 \times 1 \times 1 \times 1,0 \\
& =584,38 \mathrm{~m}^{2}
\end{aligned}
$$

Dari perhitungan luasan berdasarkan kebutuhan area parkir yaitu sebesar 584,38 $\mathrm{m}^{2}$ dan luasan lapangan parkir yang tersedia sekarang $1.600 \mathrm{~m}^{2}$, jadi luasan dan kapasitas lapangan parkir siap muat yang tersedia pada saat ini masih memadai.

\section{Analisa Kebutuhan Gangway}

Berdasarkan hasil pengamatan di lapangan pada saat survei dilakukan untuk fasilitas gangway di Pelabuhan Penyeberangan Tanjung Kalian, Penumpang yang akan menuju ke kapal pada saat proses muat dan menuju keluar pelabuhan pada saat proses bongkar, penumpang pejalan kaki harus melewati jalan yang dilewati oleh kendaraan. Keselamatan serta kenyamanan pengguna jasa merupakan salah satu tanggung jawab pihak pengelola pelabuhan untuk melayani pengguna jasa yang akan menyeberang.

Untuk meningkatkan pelayanan yang ada di Pelabuhan Penyeberangan Tanjung Kalian dan untuk menjamin keselamatan penumpang pada saat penumpang memasuki kapal maka diperlukannya pembangunan terhadap jalan penumpang untuk keluar masuk dari dan ke kapal yaitu berupa jalan khusus penumpang atau gangway.

Untuk melaksanakan pembuatan gangway maka dibutuhkan acuan dalam hal penentuan lebar dan tinggi dari gangway tersebut, dalam hal ini acuan atau referensi yang digunakan yaitu panduan pembuatan gangway yang berasal dari salah satu lembaga kelautan internasional yaitu The Oregon State Marine Board. Berikut ini adalah standar ukuran minimum untuk pembangunan gangway di Pelabuhan Penyeberangan Tanjung Kalian :
a. Lebar Gangway
: 1,5 meter 


$\begin{array}{lll}\text { b. } & \text { Tinggi Pagar di Gangway } & : 1 \text { meter } \\ \text { c. } & \text { Tinggi Atap } & : 2,50 \mathrm{~m} \\ \text { d. } & \text { Tinggi Dari Permukaan Tanah } & : 4 \mathrm{~m}\end{array}$

\section{Keterangan :}

Tinggi gangway dari tanah disesuaikan dengan tinggi maksimum tempat kendaraan di kapal pada kapal KMP. Satya Kencana yaitu 3,95 meter. Untuk acces bridge atau jembatan penghubung ke kapal penentuan lebar acces bridge disamakan dengan lebar gangway.

Berdasarkan hal tersebut dan untuk keselamatan penumpang serta untuk meningkatkan pelayanan yang ada di Pelabuhan Penyeberangan Tanjung Kalian maka perlu dibangunnya jalan khusus penumpang menuju ke kapal atau gangway, dengan adanya jalan khusus untuk penumpang tersebut maka pengguna jasa pelabuhan yaitu khususnya pejalan kaki akan merasa lebih aman dan nyaman saat akan menuju ke kapal.

Di bawah ini adalah gambar rencana pembangunan dan penempatan gangway untuk penumpang yang langsung menuju ke deck penumpang di kapal.

\section{Analisa Loket Penumpang}

Kondisi pada Pelabuhan Penyeberangan Tanjung Kalian pada saat ini posisi loket penumpang yang berada setelah ruang tunggu sehingga menyebabkan banyak penumpang yang menunggu di areal dermaga dan rumah moveable bridge. Padahal fasilitas ruang tunggu pada pelabuhan penyeberangan Tanjung Kalian sudah ada dan cukup baik. Dibawah ini merupakan kondisi existing letak loket penumpang kapal ferry pada pelabuhan penyeberangan Tanjung Kalian:

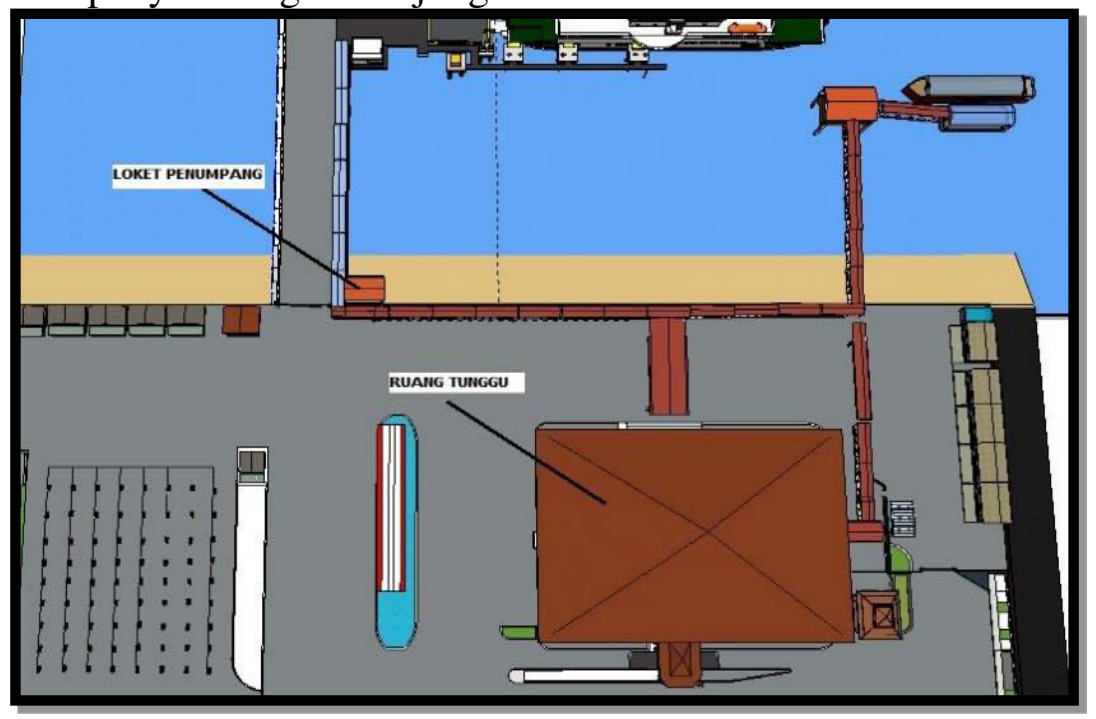

Kondisi Existing Letak Loket Penumpang

Dari gambar diatas dapat dilihat bahwa letak dari loket penumpang berada setelah ruang tunggu, sehingga membuat fungsi dari ruang tunggu menjadi kurang efektif. oleh karena itu, maka perlu dilakukan penataan / penempatan kembali dari loket penumpang kapal Ro-ro. Untuk melakukan analisa penempatan posisi loket penumpang, maka penulis mengambil referensi berdasarkan pada Peraturan Direktorat Jendral Perhubungan Darat Nomor : SK.2681/AP/DRJD/2006 tentang Pengoperasian Pelabuhan Penyeberangan, yang menjelaskan penempatan loket penumpang sesuai dengan peraturan diatas dimana semestinya loket penjualan karcis adalah sebelum 
ruang tunggu sehingga ketika kapal suadah siap untuk muat, maka para penumpang tidak berebutan untuk membeli karcis karena sudah dibeli sebelum masuk ke ruang tunggu, adapun pada pelabuhan penyeberangan Tanjung Kalian sekarang dimana posisi penempatan ruang tunggu adalah sebelum loket tempat penjualan karcis penumpang, sehingga berakibat pada para penumpang berebutan untuk membeli karcis ketika kapal mulai sudah siap untuk muat dan berbarengan dengan kendaraan yang akan masuk ke kapal.

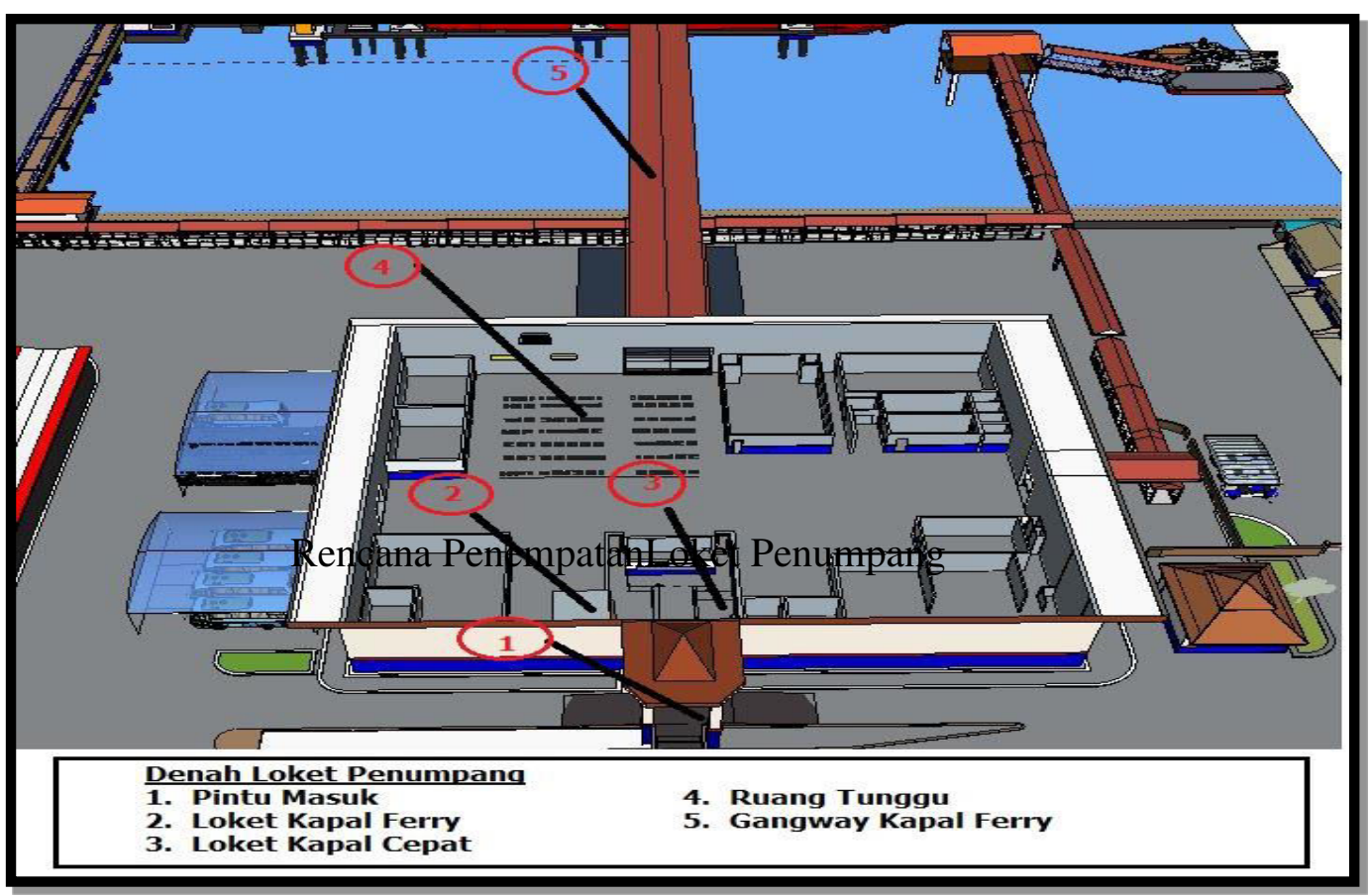

\section{Fasilitas Darat}

Setelah mengetahui kondisi existing yang terjadi di pelabuhan penyeberangan Tanjung Kalian, menganalisa kondisi yang terjadi serta mengidentifikasi masalah yang terjadi maka diusulkan untuk pemecahan masalah yang ada.

\section{Terminal Penumpang}

Pelabuhan penyeberangan Tanjung Kalian masih kekurangan 86 kursi, dari hasil analisa jumlah kursi 278 buah, dengan kondisi existing 192 kursi maka diketahui kekurangan kursi yaitu 278-192=86kursi agar semua penumpang yang akan berangkat mendapatkan tempat duduk.

\section{Gangway}

Belum adanya fasilitas gangway di pelabuhan penyeberangan Tanjung Kalian sehingga penumpang dan kendaraan tidak terpisah saat masuk kapal yang mengakibatkan waktu bongkar dan muat menjadi terlambat, serta sebagian penumpang untuk masuk kapal melalui sisi samping dengan melewati fender dermaga terlebih dahulu. 


\section{Perkantoran}

Sekarang ruang kantor yang ada luasnya $222 \mathrm{~m}^{2}$, sedangkan berdasarkan perhitungan diperlukan hanya seluas $60,48 \mathrm{~m}^{2}$

\section{Fasilitas Penyimpanan Bahan Bakar (bunker)}

Di Tanjung Kalian tidak disediakan Bunker karena sudah ada di Pelabuhan Tanjung Api-api yang merupakan pasangan pelabuhan Tanjung Kalian.

\section{Instalasi air, listrik dan telekomunikasi,}

Untuk instalasi air bersih terdiri dari satu unit tangki dengan apasitas 10.300 liter, untuk listrik terdiri dari rumah Genset seluas $140,8 \mathrm{~m}^{2}$ dan dua unit Generator set terdiri dari $200 \mathrm{kVa}$, sedangkan untuk telekomunikasi sudah tersedia dengan kondisi yang cukup baik.

\section{Akses jalan dan/atau jalur kereta api,}

Karena di Pelabuhan Tanjung Kalian tidak ada Kereta Api, sehingga pelabuhannya tidak dihubungkan dengan Jalan Kereta Api.

\section{Fasilitas pemadam kebakaran,}

Di Pelabuhan Tanjung Kalian telah disediakan fasilitas Pemadam Kebakaran sebanyak 10 unit .

\section{Tempat tunggu kendaraan bermotor sebelum naik ke kapal.}

Lapangan parkir siap muat disediakan seluas $1600 \mathrm{~m}^{2}$, sedangakan hasil perhitungan dibutuhkan hanya 584,38 $\mathrm{m}^{2}$.

Berdasar bahasan diatas maka ada beberapa permasalahan yang tidak sesuai dengan ketentuan peraturan yang berlaku, sehingga menjadikan keberangkatan kapal kedua sampai dengan kelima, terlambat rata-rata 60 menit, diantaranya penyebabnya adalah karena ketidak beradaannya Gangway dan kesalahan penempatan loket penjualan karcis penumpang.

\section{KESIMPULAN DAN REKOMENDASI}

\section{Kesimpulan}

Berdasarkan hasil pengamatan di lapangan pada saat survei dilakukan beberapa permasalahan yang mempengaruhi keterlambatan keberangkatan Kapal adalah;

1. Belum adanya gangway di Pelabuhan Penyeberangan Tanjung Kalian, maka para Penumpang yang akan naik ke kapal pada saat muat dan yang akan turun mereka harus melewati jalan yang dilewati oleh kendaraan, maka ketika para penumpang akan naik kendaraan sudah muat terlebih dahulu maka mereka harus lewat dinding dengan melalui fender yang berbahaya dan tidak nyaman, kemudian juga ketika penumpang akan turun dari kapal mereka keluar setelah beberapa kendaraan keluar terlebih dahulu sehingga waktu bongkarnya lebih lama.

2. Penempatan loket penumpang yang mana penempatannya setelah ruang tunggu, sehingga ketika ada pemberitahuan dari petugas kapal bahwa kapal sudah siap 
untuk muat maka, para penumpang baru menuju loket untuk membeli karcis sehingga terjadi antrian, yang apabila kita menghitung waktu yang diperlukan untuk pembelian karcis tersebut berdasarkan data yang kami dapat rata-rata 2,8 menit/orang, penelitian terdahulu rata-rata 2,6 menit/orang, lalu SOP pelabuhan 3,0 menit/orang, sedangkan penumpang rata-rata 62 penumpang/trip, sehingga dibutuhkan waktu 2,6 menit x $62=161,2$ menit atau 2 Jam 41,2 menit, sedangkan kapal sandar diberi waktu hanya 120 menit, maka untuk lima kali keberangkatan kapal dari pelabuhan Tanjung Kalian, Muntok hanya kapal pertama saja yang tidak bermasalah dengan keterlambatan.

3. Tidak dioperasikan Jembatan Timbang dan penempatannya setelah loket penjualan karcis kendaraan, yang sesungguhnya fungsi jembatan timbang tersebut adalah untuk stabilitas muatan di atas kapal dan juga ketinggian kendaraan yang sesuai dengan kemampaun kapal, maka apabila tidak dioperasikannya jembatan timbang tersebut akan mempersulit penempatan kendaraan guna untuk stabilitas muatan di dalam kapal.

\section{DAFTAR PUSTAKA}

UU. No. 17 Th. 2008 Tentang Pelayaran.

PP. No. 61 Tahun 2009 tentang Kepelabuhan.

PM. Perhubungan No. 27 tahun 2016 tentang Pengaturan dan Pengendalian Kendaraan yang Menggunakan jasa Angkutan Penyeberangan.

Peraturan Menteri Perhubungan Nomor 29 Tahun 2016 Tentang Sterelisasi Pelabuhan Penyeberangan.

Keputusan Direktorat Jenderal Perhubungan Darat Nomor SK.2681/AP.005/ DRJD/ 2006 tentang Pengoperasin Pelabuhan Penyeberangan.

Abubakar, dkk (2010) Pengantar Transportasi Penyeberangan,

Herjan Kenasin (2010) Karakteristikdan Operasi Angkutan Sungai, Danau dan penyeberangan, Raja Grafindo Persada.

Kramadibrata,S.(2002) Perencanaan Pelabuhan ITB, Bandung,

Miro, Fidel, (2010) Perencanaan Transportasi, Universitas Bung Hatta, Padang.

Nasution, MN (2008) dalam bukunya Manajemen Transportasi.

Poerwadarminto, W. (1986) Kamus Besar Bahasa Indonesia, Balai Pustaka, Jakarta. 
